\title{
Enhancing Students' Academic Performance in University System: The Perspective of Supplemental Instruction
}

\author{
Oyinlola Omolara Adebola \\ University of the Free State, Republic of South Africa \\ https://orcid.org/0000-0003-2768-4273 \\ Cias T. Tsotetsi and Bunmi Isaiah Omodan \\ University of the Free State, Republic of South Africa \\ https:// orcid.org/0000-0003-1035-3339 \\ https://orcid.org/0000-0002-9093-3108
}

\begin{abstract}
Following the dwindled academic performance of first-year undergraduate students in the universities as observed by the researchers and confirmed by the literature, the study problematised Supplemental Instruction (SI) mechanism as a tool to enhance students' performance. Supplemental Instruction, according to this study, is the kind of supplementary academic supports rendered to students to enhance their performance. In order to achieve this, this study explored the challenges with the use of Supplemental Instruction along with the possible solutions to the problems. Social constructivism was used to theorise the study. Participatory Research (PR) was adopted as a methodology for the study because it involved the coming together of the concerned people to participate in problem definition, problem assessment, implementation, and evaluation. Unstructured interviews were used to generate data from the participants who were facilitators and students as co-researchers with the use of audiotape recorder. The participants for the study included first-year students at the selected university, the SI coordinator, two tutors for various modules and their lecturers. Thematic analysis was adopted to categorise, interpret, and analyse the generated data because it involved the reflection of categorised objectives. The study found out among others that; inadequate planning and lack of collaborative engagement were the major challenges while training and retraining of SI personnel and collaborative engagement were the suggestible solutions to ameliorate the problems. However, the study, in its conclusion, significantly enhances the university's reputation and increases the quality of its outputs in terms of students' academic performance through the use of SI.
\end{abstract}

Keywords: first-year students; academic performance; university system; supplemental instruction 


\section{Introduction}

University is an institution of higher learning providing facilities for teaching and research and authorised to grant academic degrees. It was further stated that a university consists of both higher institutions of learning and a community of scholars (Sintayehu, 2018). Meanwhile, it has been said that university students are not doing well in their performance. It was revealed in a study that was conducted by (Rajendra \& Sue,2015), that some of the reasons why students do not perform well and the increase in the rate of drop out in university were finances, lack of qualified lecturers, lack of academic support from the university and wrong choices of specialisation to mention but few. However, this study is to bridge the gap by providing academic assistance in the form of Supplemental Instruction for those students who are especially facing poor academic performance in university. This kind of academic support works in a way that the senior students who have passed the specific modules are employed by the university to tutor the junior students (Olstedt, 2005).

According to Medina (2003), Widmar (1994), Magin and Churches (1995), Anderson, Boud and Sampson (1996), Potter (1997), and Wood (1997), SI is a wellestablished program to promote students learning. It was estimated that the use of SI had increased significantly, and a decade ago was already used at more than 1500 university colleges and all over the world (Martin 2008). According to Olstedt (2005) and Arendale, (1997), SI is not just an approach, but it is a belief system to learning. Inner action and curiosity are the driving forces, and the main focus is on self-determination and collective learning. It has been used in higher institutions, including the University of the Free State, to support students in their learning activities.

From the above, we see Supplemental Instruction (SI) as an academic support program that employs successful senior tertiary students to facilitate peerlearning sessions with first-year students. SI is mostly attached to highly populated modules (Philip, Jacques, Jane \& Kym 2014). It has been observed by researchers that students with average and with high SI attendance do significantly better in terms of overall first-year credit performance than students with scanty attendance (Etter, Sandra, Burmeister \& Elder; 2001). It was further noted by (Joakim, Leif \& Lise 2012) that students with low, average, and high prior academic achievement all benefit from attending SI sessions. SI complements the regular studies of a course. The idea behind it was that learning a subject should be enhanced by the exchange of thoughts and ideas between students. This is realised by them asking questions, initiating work in small groups,-and coordinating the presentation of conclusions. These senior students attend training courses on how to be SI leaders and provided with tools to use during these sessions (Joakim, Leif \& Lise 2012).

Michelle (2012) concluded that SI sessions improved students' performances in the semester that they attended SI sessions. It was noted that SI is a useful approach to support student success. The U.S. Department of Education asserted that participation in SI was correlated with higher mean grades, lower failure, and withdrawal rates, as well as higher retention and graduation rates (Philip, 
Jacques, Jane \& Kym, 2014). Based on extensive research, it was concluded that in entry-level courses, SI contributed to increased pass rates, as well as in higherlevel courses (Peterfreund, Rath, Xenos \& Bayliss, 2008). SI was associated with higher graduation rates and thus, student retention (Bowles, McCoy \& Bates, and 2008; Crosling, 2018). While the studies mentioned here all point to the successes of SI, the lack of students' success in a large-scale first-year module offered at universities in South Africa, even with SI implemented, led to the need for closer scrutiny. From the above, we argue that Supplemental Instruction is a kind of academic support rendered by the university to assist some students who have difficulties in passing specific modules, in helping classes with a large number of students and also to boost the academic performance of students. Therefore, the problem of the study is that in some of the modules offered to large numbers of first-year students, it was discovered that despite the intervention of the university through SI, students' grades were still below average. This happens in almost all supplemented modules offered by first-year students. The period from 2015-2019 has shown that students were performing averagely. Thus, there is a need to explore why the academic performance of first-year students did not improve in the period under review 2015-2018 A lack of expected improvement prompted me to pursue this study. The researchers observe this problem while she was tutoring the module.

\section{Theoretical Framework}

Social constructivism was used as a theoretical framework for this study. This theory is grounded in knowledge construction (Vygotsky, 1978). Vygotsky, the father and founder of social constructivism, believed that the origin of knowledge construction is the social interaction of people, based on the sharing, comparing, and debating amongst learners and mentors (Dagar \& Yadav, 2016). This is a highly involving process of learning, focused on both learners and teachers, improving their cognition to help others find meaning by means of the discourse. Therefore, knowledge was seen not to exist-in isolation from social and cultural settings (Vygotsky, 1978; Dagar \& Yadav, 2016). This viewpoint was in line with the conclusion of Gergen (1995) that the basic principle behind social constructivism pertains to knowledge was phrased through social interaction and the result of social processes.

This theory is relevant to this study because it substantiates the fundamental importance of recognising diverse opinions in the classroom with unrestricted social interaction among the classroom stakeholders such as SI leaders, facilitators, and students. From the above, one could deduce that Social Constructivism believes that students learn best when collaborating with their peers. Since the study is about using SI to enhance the use of academic performance of first-year students, Social Constructivism as a theory is relevant to the study. It is relevant because it enables both facilitators and students to engage in socially constituted interrelation opportunities to construct and interchange knowledge through their social discourse. Following ChambersTurner (2010) that social constructivism allows students to share knowledge among themselves, which in our views enhances academic performance and leads to the increase in the graduation rate, lowers drop-out rate, and also ensure 
retention rate. In other words, social constructivism through collaborative share knowledge in social context enhances Supplemental Instruction towards student academic performance. Dagar and Yadav (2016) further justified the collaborative knowledge sharing that a highly involving process of learning is focused on both learners and teachers, improving their-cognition to help others find meanings to the discourse.

\section{Research Question \& Objectives}

The following research question was formulated to pilot the study:

How can SI be used to enhance the academic performance of first-year students in Universities?

To achieve the piloting question, the following objectives were raised to guide the study:

- To identify challenges with the use of SI in enhancing the academic performance of first-year students in Universities.

- To explore solutions to the challenges facing the academic performance of first-year students in Universities.

\section{Methodology}

\subsection{Research Design}

This study adopted Participatory Research (PR) design; the nature of the research design choice for this study is based on the premise that; there is a need for individuals faced with the problem of the study to be part of the solution process (Jarg \& Thomas, 2012). PR is a research process where the concerns people participate in one or more of the following: intervention planning, problem definition, problem assessment, implementation, and evaluation (Hughes, 2003; Ho, 2002). PR is also seen as a collective inquiry into a social situation to improve the rationality and justice of participants' social practices. In our view, it enhances participants' critical consciousness and resources, such as knowledge, social networks, and their sense of community (Nelson, Ochocka \& Griffin, 1998; FosterFishman, Pennie, Kristen, Lauren \& Christina, 2010). By implementation, the participants were treated as equals to the researcher and also seen as empowering and liberating (Aldridge, 2017). Its ideological orientation is liberal, focusing on the improvement of professional practices. This is to say that the design is highly committed to democratic engagement, transparency, and openness, cooperative and communitarian ethos, inclusion, and multiculturalism (Dale, 2001). PR is, therefore, appropriate for this study because of its involvement with the people. The people in this study are the academic researchers and the researched. They were brought together to find a lasting solution to the trajectory of Supplemental Instruction and its correlational effect on Academic performance of Students.

\subsection{Data Generation Method and Process}

An unstructured interview, also called an in-depth interview, was used for data generation in this study. An unstructured interview, according to (Dana, 2013) is the best to discover important information about a topic and focuses on a particular theme. We try as much as possible to remain transparent to new and unexpected phenomena instead of imposing will on the participants (Sandy, 
2011). All the participants in this process were seen as being reflective of real-life experience and social reality. The data generation process involved having meetings with co-researchers, which was aimed at clarifying the purpose, problem, and process of the study. Interview with them focused on challenges and solutions faced by the use of SI to enhance the academic performance of firstyear students in the university. After the generation of data, the researcher presented the report to co-researchers/participants to check, add inputs, and suggest corrections. Participants had the opportunity to check whether the data generated were interpreted correctly. In addition, participants were allowed to use any language that they were comfortable with during the interview.

\subsection{Participants and Selection of Participants}

The participants in the study included two first-year students, two lectures, two tutors, and two SI leaders from the selected university. They assisted with their experiences to address the issue in SI. Two first-year students were chosen because they offered the module under investigation. The two lecturers chosen were responsible for teaching the module for many years with adequate experiences regarding the selected module. Also, the two supplemental instruction leaders were selected because they were responsible for the administrative aspect (recruiting, salary, assessment) of all tutors in the university. They were able to share their experiences in terms of challenges, success, and their views about using SI in a university.

\subsection{Method of Data Analysis and Ethical Consideration}

Thematic Analysis (TA) was adopted to analyse the generated data. Nowell, Norris, White, and Moules (2017) opined that TA should be a basis for analysing data because of its core value for conducting qualitative analyses. It is an approach for categorising, reporting, organising, defining, and analysing themes found within a data set (Omodan, 2019). The thematic analysis made it easy for us to analyse data because it makes data to be easily understood, it provides conveniently detailed, especially when summarising critical concepts of a huge data set (Braun \& Clarke, 2006). The ethical committee of the University of the Free State approved the study with approval number UFS-HSD2018/1132. The consent of the participants was sorted for, and they were provided with information that, during, and after the study, their information and utterances will be kept confidential from the third parties. They were also assured that their names would not be disclosed to the third party and that their responses would remain anonymous.

\subsection{Presentation of Data and Discussion}

In order to enhance the academic performance of first-year students in a university with the use of SI, below were some of the challenges and possible solutions that were found during the study; Inadequate planning and lack of clear communication as challenges, training and retraining, and collaborative engagement were found as solutions. For anonymity sake, the participants were represented using A1 \& A2 (Lecturers), B1 \& B2 (Tutees), C1 \& C2 (Tutors), and D1 \& D2 (SI Leaders/Personnel). 


\section{The challenges with the use of SI to enhance the academic performance}

\subsection{Inadequate planning as a challenge}

For any organisation to succeed, there must be proper planning. Planning was one of the challenges facing the implementation of SI in higher institutions of learning and could hinder the progress of any programme if not taking into consideration. When there is no planning, all academic programmes, including tutorials, are at risk, and this means that students' academic performance cannot be enhanced. This problem of planning is not limited to South Africa Universities alone, but as stated by the Kenya Education Sector Support Programme (KESSP) in a research conducted by (Education Management Capacity Assessment, 2005). Below were the comments from the participants:

Participant A2: "one major is about tutor clashes students who are also tutors might miss tutorials we need to find a way because if a tutor who is also a student has to attend class and tutor as well can be a challenge."

According to participant A2, one major challenge associated with a lack of constant planning was the issue of timetable clashes between tutors and tutees and or among all the faculty in the university. It has been in existence for years and seems to be seen as a normal thing to happen. It happens most of the time that the time a tutor supposed to be in tutorial sessions clashed with the time he/she was having a lecture, (Moleko, Hlalele \& Mahlomaholo, 2014). In other words, class attendance could also be of assistance in solving timetable clashes in relation to what participant $A$ said.

Participant D2: "Timetable clashes with that of the tutors, which renders our tutorials at some point not to be important because they are voluntary by nature. Some students don't attend tutorials or neglect tutorials, but we can't blame them because this happens as a result of timetable clashes."

Participant D2 who happens to be one of the SI leaders emphasised that even though timetable clashes is a challenge that is rendering their effort worthless, continue to say that attending tutorial is voluntary; that is, it is not a must for students to attend. Timetable clashes make it difficult for SI to blame or punish any student who decides not to participate. This is a big challenge in such a way that the students who are tutoring are clashing with the students (tutees) to be tutored. Even though SI is responsible for managing tutorials, they are unable to profile any solution to this challenge just because the university as a whole manages the timetable through the office of Examination and records. This shows that the department responsible for the payment of tutors is seen to be wasting resources like money to a programme that cannot be controlled or managed well.

The above analysis confirms that inadequate planning, such as clashes of timetable, class attendance, and assuring non-performing tutors, is confirmed to be a severe challenge to the implementation of SI. This is in support of Alemu (2019). Even this is also against the principle of social constructivism that says that students should be learning collaboratively among themselves through interaction and engaging in critically thinking. However, if there is no adequate planning from both students and tutors, the implementation of SI will be a 
challenge (Amineh \& Asl, 2015). Nevertheless, this does not mean that there was no planning at all, but instead, the study proved that preparation was not sufficient enough to implement SI easily.

\subsection{Lack of Clear Communication}

Effective communication is an essential factor in the teaching and learning process; without it, SI is might lead to fruitless efforts. It was another challenge that hindered the implementation of Supplemental Instruction in universities and other institutions of learning. When communication is not clear, students, especially first-year students who are just finding their ways into higher institution environments, are lost and do not know what to do concerning a particular instruction. In Supplemental Instruction, communication among all the stakeholders involved is considered to very vital, and this includes; tutors, students (tutees), lecturers, and SI leaders (coordinators). Meanwhile, a lecturer supposed to brief tutors what they ought to teach in the class, and at the same time tutor should report back to the lecturer and SI coordinators. This channel of communication keeps SI personnel abreast of what is happening at tutorial sessions and informed them of the next action or strategy to take in order to improve this support system. Participants also agreed that the lack of communication and relationship among collaborators hindered the success of SI, which made it a challenge; this was supported by SI (Moleko et al., 2014). Below are the comments from participants;

Participant D2: "There is no proper communication between these parties such that most students miss their tutorials."

Participant A2: "Communication between the lecturers and tutors been lacking can also be a challenge that will really require a way in which it is coordinated better."

Proper communication among all the stakeholders was also raised to be a challenge facing the implementation of SI. It is not that there was no communication but that the channel at which communication was wrong, or there was no effective communication. Participant D2 was saying that the reason why students who attend tutorials do miss classes was because of improper contact between students and tutors. The same problem was echoed by participant A2 that the lack or inadequate communication was as a result of the lack of coordinated communication, that is, improper or ineffective communication. The participant A2 went further to say that apart from the issue of rapport between them, it was also reported that lack of communication is another challenge.

Lack of clear communication was discovered in the data analysis process to be one of the challenges facing the implementation of SI. Clear communication is an aspect in academics that needs careful attention either horizontally or vertically if teaching and learning should be successful. It emanated from the data that lack of clear communication between students and tutors, students and lecturers, SI personnel and tutors, and even between SI personnel and lecturers is not sufficient. Research made it clear that due to lack of clear communication, students give reasons why tutorial sessions are not appealing to them and see no point in attending (Malm, Bryngfors \& Mörner, 2012). Social constructivism theory states that one of the significant factors that determine the success of peer learning is 
language; that is, clear and effective communication helps students to function well when interacting with other peers and even in the community (Gergen, 1995). Therefore, the findings show a contradictory phenomenon where the current reality indicates that there is a lack of clear communication among the SI personnel and students.

\section{The Suggestible solutions to the challenges to enhance the academic performance}

\subsection{Training and Retraining of SI personnel}

According to Mohamed, Saud and Amhad (2018), the place of training of people should be given a priority of constant attention to training. Training and retraining is an essential key that should not be neglected in every aspect of academics, including SI personnel and facilitators. One of the major goals of SI was to help students who are not doing well in specific modules, and for this goal to be achieved, the study revealed that there was a need for training and retraining of facilitators. Another reason why training was needed was to keep facilitators abreast and to be a master of their work (content knowledge), methods of teaching, and strategies they could employ to make teaching and learning interesting and engaging. These facilitators were also students who were doing their third or final year, which means that they were still undergraduates students. Therefore, if the point mentioned above could be implemented, there will be an improvement from both sides, students will be motivated to come to the tutorial session, and the academic performance of students will be enhanced through supplemental instruction support. The following statements from the coparticipants support our point:

Participant A1: "pairing experienced tutors with inexperienced tutors, For example, yourself you were sort of mature compared to most of the tutors you could handle a particular group alone, but with other tutors, we used to pair them because some of them were not necessarily experienced." I think for me, the experience of a tutor plays an important role.

Participant A2: "Another solution for this challenge is the tutors can be trained to utilise podcasting for e-learning." Whereby they will be trained to capture themselves planning for the lesson on their laptops, recording themselves and send to the students via the Blackboard so that they can view on their own time."

Participant B1: "Another condition is to keep on training the tutors. They must receive training on a regular basis in order to keep them abreast of the changes which are there of tutors."

Participant B2: "One section could be of maintaining experienced tutors if they are experienced we do not struggle too much but as well lecturers, we may not be shy again to expel those who do not do well because if you do not expel them, even those who are doing well they can see that if you don't do well, it does not matter."

From the statement of participant A1, it was believed that if a tutor who was experienced could be paired with an inexperienced tutor in order to learn from each other. From the researchers' point of view, it was necessary even for the 
experienced tutor to be given training and retraining before pairing with an inexperienced tutor. It was also found that training and retraining of tutors and even staff should be a continuous practice in academics generally. (Enaibe, 2012; Joy, Nneka \& Idugbo, 2013).

Participant B1 opined that tutors could be trained on how to use podcasting for elearning as solutions for the challenge of over enrolment and lack of venues. (Podcast is kind of video files which a user can download to listen to). Because participant B1 was talking about training tutors being able to use podcasts to reduce in order to overcome the challenge, but there was a need for training. This means that tutors can record themselves on what they wanted to facilitate and upload it to Blackboard where students can both receive the content and master them before or after tutorial sessions. In this way, SI could be enhanced tremendously. To achieve this, the researchers suggested that tutors must be trained on the use of podcasting 'for e-learning'; this suggestion seems to be a good one, not only for the success of SI but also for academic staff as well if implemented.

Therefore, it was found that the training and retraining of SI personnel like tutors and SI coordinators are very important in making SI implementation successful. It was revealed that constant training is a requirement for any organisation that wants to achieve its goal. This is, according to Mohamed, Saud, and Amhad (2018). It is important that tutors and SI personnel, in particular, are put to constant training from time to time to be productive, creative and even master the content to be shared with the tutees during tutorial sessions. When they know what is expected of them and are empowered to do so, they will be encouraged and gain confidence in class.

\subsection{Collaborative engagement and communication}

Collaborative learning is a method of learning where groups of students coming together to share their knowledge in solving problems, engage in collaborative activities to learn from one another. This means that one of the reasons for Supplemental Instruction, which is a support system in any higher institution of learning, was to assist students who were having challenges in some specific modules. Therefore, for SI implementation to be effective, there should be collaborative learning among all the participants, including tutors where everyone is involved, as we all know that "learning is doing". In this process, it will be easier for any tutor to know where students were having challenges that can be attended to immediately. After this study, the researchers discovered that collaborative learning was fun, interesting and made teaching and learning to be meaningful in the hand of a skillful tutor. Apart from been interesting, students were eager to attend the next class and will not want to miss it for anything. Collaborative learning has advantages such as students developing higher-level thinking, improved communication skills, and they are able to conduct themselves and also develop leadership skills. SI believes that collaborative learning is a method that both student and tutor could look into because of the attributes to enhance the academic performance of students. The esponses from the co-participants are as follows: 
Participant B1: "On the issue of not participating, students need to be encouraged to take their tutorials seriously. Most of them think that it's just a way of punishing first-year students."

Participant B2: "On the issue of lack of flow of information-all the stakeholders involved must have a workshop/training where they are told to work together because they all need to collaborate in order to have effective tutorials sessions."

Participant C1: "The issue of communication there is need for the tutorial team to emphasise the importance of proper planning so that planning can be consistence between the two because communication is key to ensure that the tutors can be able to facilitate the relevant content in the tutorials."

Participant C2: "Flow of information among all the stakeholders involved must have a workshop/training where they are told to work together because they all need to collaborate to have effective tutorials sessions."

Participant D1: "Most of the time the students do not show up if you ask they blame the lecturers that they were not introduced." "If you dig deeper, you will realise that there is no communication between the tutors and lecturers are not okay."

The comments from participant B1 about students not participating in the tutorial session in my understanding, he/she was saying that if students could be encouraged, maybe there will be a change in the way they view tutorials. It was believed that first-year students see tutorials as a way of punishment, and because of that, they see no reason to engage during a session that was supposed to be collaborative learning. Since we are discussing the solutions to SI, one of the suggestions is student's encouragement, according to the participant, could be one of the solutions. Participant B2 suggested that all the stakeholders involved in SI should be having workshops/training regularly. Since the lack of communication and collaborative engagement was mentioned to be part of the problems facing SI.

Furthermore, Participant B2 believed that if SI personnel, such as SI coordinator, lecturer, tutor and tutees (students) could hold a workshop often to discuss challenges that tutor faced during the tutorial and provide solutions, to raise issues related to tutorials and how they can support one another in assisting students who attend the tutorial. According to the statement, it sometimes happened that tutors do go to class without knowledge of what to facilitate, and this made tutors to be ridiculed, but if there is meeting from time-to-time, among these people, indeed, students who attend tutorial will be motivated and eager to always attend. With this solution, the academic performance of first-year students will be enhanced through SI, and teaching and learning will also be effective. I strongly agree with them the above statements because if there is effective communication among all the stakeholders, workshops from time to time, and proper planning, certainly SI will be enhanced, and the academic performance will definitely be improved. 
The collaborative engagement was, therefore, found to be one of the suggested solutions to the SI implementation. Collaborative engagement could be in the form of peer learning, group work, cooperative learning, etc. Aminneh and Ast (2015) said that when learning under the assumption of Social Constructivism, knowledge should be constructed through students interacting with one another because knowledge does not take place in isolation, but rather in a social context. Social Constructivism states that students are supposed to be critical thinkers and constructors of their knowledge among themselves through collaborative engagement (Kuka, 2000).

\section{Conclusion and Recommendations}

Based on the findings, we, therefore, concluded that the challenges facing the implementation of SI include inadequate planning, overcrowded as a result of over enrolment, lack of communication, and collaborative engagement. In that manner, the suggested solutions to these challenges remain training and retraining of SI personnel, collaborative engagement and communication, and Up-to-date evaluation and feedback. The study concluded that if the suggested solutions can be implemented, then SI implementation will be possible in a university. In summary, the study concluded that using Supplemental Instruction to enhance the academic performance of first-year students is doable if the above findings can be implemented in university. Of course, the use of SI in a university as a supporting educational system is not a strange programme. Still, the aspect of using it to enhance first-year students academic performance needs more attention from universities. The study recommends that supplemental Instruction should be prioritised to improve first-year students academic performance. The research also suggests that both students (tutees) and tutors need to be motivated in any form. There is a need for constant training and retraining of all SI personnel and especially tutors.

However, the following recommendations were made according to the findings:

1. Recommendation for University: Those universities with the same academic experience ensure that educational facilities such as mentioned in the findings are provided. Effective communication among lecturers, tutors, and tutees is essential as this was found to be a barrier that has to improve. Adequate funding is a must for universities to run smoothly as it is supposed to be. So the study suggests that universities should improve in this aspect. During winter, it is always challenging to write as most universities in South Africa write the midterm examination this time. Therefore, the study suggests that more classrooms are built to accommodate a large number of students and should be conducive enough for both staff and at least 1000 capacity of students since the campus is growing fast. Alternatively, universities should consider capping the number of first-year students.

2. Recommendation for Supplemental Instruction Department: That any department responsible for the management and operation of SI system should ensure that there are training and retraining for their staff and tutors/facilitators. Not only that, but they must also device new meaning following dynamism as regards university environmental factors and change. Since the department is responsible for the recruitment of tutors, they must 
ensure that competent tutors are recruited. The provision of feedback and evaluation from time-to-time among the staff and the tutors must also be ensured. The study also suggests that tutorials should be made compulsory for not only students who have difficulties in some modules, but especially first-year students. Attendance should also be taken and monitored by SI coordinator. If a university wants to enhance students performance, there should be adequate planning on the ground.

3. Recommendation for Tutor/Facilitator: Tutors must ensure that they prepare before going for tutorial sessions as lack of preparation was mentioned as one of the reasons why tutees feel discouraged to attend tutorials. They should incorporate various strategies to engage their tutees to work either collaboratively or individually. They should be accountable and responsible for each tutee under their leadership.

4. Recommendation for Tutee/Student: That tutorials should be seen as a roadmap to their success and not as a punishment. They should always see tutorials as a platform where they can improve themselves both academically and socially. Since tutorial sessions are organised for students, then it should be seen as a place to ask questions and participate collaboratively in any form of academic discussion.

\section{References}

Akaranga, S. I., \& Ongoinga, J. J. (2014). The supervision of woman by religion: A Kenyan example. Journal of educational policy and entrepreneurial research, 1(4), 48-60.

Akaranga, S. I., \& Ongonga, J. J. (2013). “Work Ethics for University Lecturers: An Example of Nairobi and Kenyatta. International Journal of Arts and Commerce, 2(8) 8-22.

Aldridge, J. (2017). Advancing participatory research. Relational Social Work, 1(2), 26-35. https://doi.org/10.14605/RSW121702

Alemu, S. K. (2019). African higher education and the Bologna Process. European Journal of Higher Education, 9(1), 118-132. https:// doi.org/10.1080/21568235.2018.1561313

Ane, J., \& Neva, L. (2018). Bridging the Supplemental Instruction Leader Experience and Post-Graduation Life. The Learning Assistance Review (TLAR), 3(1), 95-144.

Arendale, D. (1997). Supplemental Instruction (SI): Review of research concerning the effective of SI from the University of Missouri-Kansas City and Other Institutions across the United States. In M. Sylvia and G. Enright (Eds), Proceedings of the 17th and 18th Annual Institutes For Learning Assistance Professionals. Tucson, AZ: University Learning Center, University of Arizona, pp. 1-25.

Barclay, C. (2018). Semi-structured interviews: Qualitative Research Guidelines Project. Retrieved from http://www.qualres.org/HomeSemi-3629.html

Boud, D., Cohen, R., \& Sampson. J. (1999). Peer learning and assessment. Assessment $\mathcal{E}$ Evaluation in Higher Education 24(4), 413-426. https:// doi.org/10.1080/0260293990240405

Bowles, T. I., McCoy, A. C., \& Bates, S. (2008). The effect of supplemental Instruction on timely graduation. College Student Journal, 42(3), 853-859.

Braun, V., \& Clarke, V. (2006). Using thematic analysis in psychology. Qualitative Research in Psychology, 3, 77-101. https://doi.org/10.1191/1478088706qp063oa

Dana, J. (2013) Belief in the unstructured interview: The persistence of an illusion. Judgment and Decision Making, 8(5), 512-520.

Dagar, V., \& Yadav, A. (2016). Constructivism: A Paradigm for Teaching and Learning. Arts Social Science Journal, 7(4), 1-4. https:// doi.org/10.4172/2151-6200.1000200 
Etter, E. R., Burmeister, S. L., \& Elder, R. J. (2000). Improving student performance and retention via supplemental instruction. Journal of Accounting Education, 18(4), 355368. https://doi.org/10.1016/S0748-5751(01)00006-9

Foster-Fishman, P. G., Law, K. M., Lichty, L. F., \& Aoun, C. (2010). Youth ReACT for Social Change: A Method for Youth Participatory Action Research. American Journal of Community Psychology, 46(1-2), 67-83. https://doi.org/10.1007/s10464010-9316-y

Gergen, K. J. (1995). Social construction and the educational process. Constructivism in Education, 17-39.

Ho, B. S. (2002). Application of participatory action research to family-school intervention. School Psychology Review, 31(1), 106-121. https:// doi.org/10.1080/02796015.2002.12086145

Hughes, J. N. (2003). Commentary: Participatory action research leads to sustainable school and community improvement. School Psychology Review, 32(1), 38-43. https://doi.org/10.1080/02796015.2003.12086179

Jard, B., \& Stefan, T. (2012). Participatory Research Methods: A Methodological Approach in Motion, 13(1), 1-35. http://dx.doi.org/10.17169/fqs-13.1.1801

Joakim, M., Leif, B., \& Lise, M. (2012). Supplemental Instruction improves grades but not persistence. Long-term impact. Journal of Developmental Education, 26, 2-8.

KEMACA. 2008. Education Management Capacity Assessment: A Pilot in Kenya, Nairobi: Kenya Education Management Capacity Assessment.

Kemmis, S. (1993). Action research and social movement. Education policy analysis archives, 1.

Latino, J. A., \& Unite, C. M. (2012). Providing academic support through peer education. New Directions for Higher Education, 157, 31-43. https:/ / doi.org/10.1002/he.20004

Jacobs, G., Hurley, M., \& Unite, C. (2008). How learning theory creates a foundation for SI leader training. Journal of Peer Learning, 1(1), 6-12.

Medina, L. (2003). Student mentoring program. Melbourne: The Royal Melbourne Institute.

Magin, D. J., \& A.E. Churches. (1995). Peer tutoring in engineering design: A case study. Education and Training, 39(9), 333-43. https:// doi.org/10.1080/03075079512331381810

Michelle, O. (2012). Supplemental Instruction Improves Grades but not Persistence. College Student Journal, 46(2), 344-349.

Mohamad, E., Saud, M., \& Ahmad, B. E. (2018). Marketing Teachers Training And Retraining Programmes In Enugu State To Educational Policymakers \& Administrators. Journal of Law, Policy and Globalization, 20, 10-22.

Moleko, M. M., Hlalele, D., \& Mahlomaholo, M. (2014). Challenges Experienced with the Implementation of Supplemental Instruction at Institutions of Higher Education. Mediterranean Journal of Social Sciences, 5(27), 740-751.

Nelson, G., Ochocka, J., \& Lord, J. (1993). “Nothing about Me, Without Me": Participatory Action Research with Self-Help/Mutual Aid Organisations for Psychiatric Consumer/Survivors. American Journal of Community Psychology, 26(6), 881-912. https:// doi.org/10.1023/A:1022298129812

Nkoane, M. M. (2012). Critical emancipatory research for social justice and democratic citizenship. Perspectives in Education, 30(4), 98-104.

Nowell, L. S., Noris, M. J., White, E. D., \& Moules, J. N. (2017). Thematic Analysis: Striving to Meet the trustworthiness criteria. The International Journal of Qualitative Methods, 16(1), 1-34. https:/ / doi.org/10.1177/1609406917733847 
Olstedt, E. (2005). Supplemental instruction, SI - Ett förhållningssätt till lärande. I SI Metod och teori [SI - A learning approach. In SI Method and Theory]. Centrum för Supplemental Instruction, 8-14.

Omodan, B. I. (2019). A strategy to enhance crisis management between students and university authorities in Nigeria ( $\mathrm{PhD}$ thesis). University of the Free State, South Africa.

Peterfreund, A. R., Rath, K. A., Xenos, S. P., \& Bayliss, F. (2008). The impact of Supplemental Instruction on students in STEM courses: Results from San Francisco. Journal of College Student Retention: Research, Theory \& Practice, 9(4), 487503

Philip, D., Jacque, V., \& Jane, K. (2014). On the Effectiveness of Supplemental Instruction: A Systematic Review of Supplemental Instruction and Peer-Assisted Study Sessions Literature between 2001 and 2010. Review of Educational Research, 84(4). https:// doi.org/10.3102/0034654314540007

Potter, J. (1997). New directions in student tutoring. Education and Training 39 (1): 24-30.

Rajendra, C., \& Sue, P. (2015). Challenges in Higher Education in South Africa. In J. Condy (Ed.), Telling stories differently. Engaging 21st century students through digital story telling (1st Edition, pp.1-6). Sun Media Stellenbosch.

Sandy, Q. Q. , (2011). The qualitative research interview. Qualitative Research in Accounting E Management, 8, 238-264. https://doi.org/10.1108/11766091111162070

Sarason, S. B. (2003). The skeptical visionary: A Seymour Sarason education reader. Philadelphia, PA: Temple University Press.

Sintayehu, K. A. (2019). African higher education and the Bologna Process. European Journal of Higher Education, 9(1), 118-132. https://doi.org/10.1080/21568235.2018.1561313

Vygotsky, L. S. (1978). Tool and symbol in child development. In M. Cole, V. John-Steiner, S. Scribner and E. Souberman (Eds.) Mind in Society-the development of higher psychological processes. Cambridge: Harvard University Press.

Widmar, G. (1994). Supplemental Instruction: From small beginnings to national program. New Directions for Teaching and Learning, 60, 3-10.

Wood, M. (1997). Mentoring in further and higher education: Learning from the literature. Studies in Higher Education, 20(1), 73-85. 